\title{
Comparación de los perfiles de transcripción de pacientes con fiebre de dengue y fiebre hemorrágica por dengue que muestra diferencias en la respuesta inmunitaria y claves en la inmunopatogénesis
}

\author{
Natalia Houghton-Triviño ${ }^{1,2}$, Katherine Martín³, Kris Giaya ${ }^{3}$, Jairo A. Rodríguez ${ }^{4}$, \\ Irene Bosch ${ }^{3}$, Jaime E. Castellanos ${ }^{1}$ \\ 1 Grupo de Virología, Universidad El Bosque, Bogotá, D.C., Colombia \\ 2 Grupo de Enfermedades Tropicales, Universidad Simón Bolívar, Barranquilla, Colombia \\ ${ }^{3}$ Center for Infectious Disease and Vaccine Research, University of Massachusetts Medical School, Worcester, \\ MA, USA \\ ${ }^{4}$ Grupo Parasitología y Medicina Tropical, Universidad Surcolombiana, Neiva, Colombia
}

Introducción. El dengue puede manifestarse como una enfermedad leve o evolucionar hasta una enfermedad grave, llamada fiebre hemorrágica por dengue, cuyos mecanismos de inmunopatogénesis no son claros.

Objetivo. Utilizar un análisis de microarreglos para identificar los genes de la respuesta inmunitaria diferencialmente expresados en niños colombianos con dengue leve y grave.

Materiales y métodos. Se evaluaron los cambios de la expresión génica de células mononucleares de sangre periférica de niños con fiebre de dengue y fiebre hemorrágica por dengue en fase aguda, mediante el microarreglo de Affymetrix HG-U133_Plus_2.

Resultados. Los pacientes con fiebre hemorrágica por dengue expresaron transcritos para interleucina 6 , quimiocinas, complemento y pentraxina 3 , al igual que inhibidores de la actividad de linfocitos (gen 3 de activación de linfocitos y catepsina L1). Un modelo de interacción desarrollado para estos genes mostró al factor tisular como central en la red generada. Por el contrario, los pacientes con fiebre de dengue expresaron inhibidores de la actividad de citocinas, complemento y leucotrienos [lactotransferrina, inhibidor peptidasa serpina del complemento $\mathrm{C}$ 1, leucotrieno $\mathrm{B}$ (4-omega hidroxilasa 2)].

Conclusiones. Los resultados podrían indicar que durante la fiebre de dengue, los inhibidores de citocinas y del complemento logran controlar el daño al endotelio y el aumento de la permeabilidad vascular, mientras que, en los pacientes con fiebre hemorrágica por dengue, la disfunción de las células inmunitarias y la acción no regulada del complemento y de las citocinas, conducen a un estado de "hipercoagulacion" y daño endotelial. La identificación del papel patógeno de las moléculas encontradas podría contribuir a la interpretación de la patogenia y al desarrollo de fármacos terapéuticos.

Palabras clave: dengue, transcripción genética, análisis de micromatrices, fiebre hemorrágica del dengue, proteínas del sistema del complemento, citocinas.

Comparison of the transcriptional profiles of patients with dengue fever and dengue hemorrhagic fever reveals differences in the immune response and clues in immunopathogenesis

Introduction. Dengue infection demonstrates a wide spectrum of clinical manifestations from mild disease (dengue fever) to severe dengue hemorrhagic fever, but the immunopathogenic mechanisms involved in disease severity are not clear.

Objective. Differentially expressed genes associated to immune response were indentified from peripheral blood mononuclear cells of Colombian children with dengue fever and dengue hemorrhagic fever.

Materials and methods. Microarray analysis was used as a tool to establish and compare transcriptional profiles of peripheral blood mononuclear cells of six children in acute phase of dengue fever and dengue hemorrhagic fever. The commercial gene chip used was Affymnetrix GeneChip HG_U133_Plus_2.

Results. Dengue hemorrhagic fever patients expressed interleukin 6, chemokines, complement proteins and pentraxin 3, along with the lymphocyte inhibitors lymphocyte-activation gene 3 and cathepsin L1. An interaction model for these genes showed tissue factor playing a central role in the network generated. In contrast, dengue fever patients expressed cytokines, complement and the leukotrienes inhibitors lactotransferrin, C1 inhibitor, and leukotriene-B (4-omega-hydroxylase 2).

Conclusions. These results indicate that in dengue fever, cytokine and complement inhibitors are able to limit endothelial damage and prevent increases in vascular permeability, whereas dengue- 
hemorrhagic fever patients have immune cell dysfunction and unregulated complement and cytokine action. This leads to "hypercoagulation" and endothelial damage, thereby increasing disease severity. Verification of the pathogenic role of the identified molecules will contribute to understanding of dengue pathogenesis and lead to rational development of therapeutic drugs.

Key words: dengue; transcription, genetic; microarray analysis, dengue hemorrhagic fever, complement system proteins, cytokines.

El dengue es una enfermedad transmitida por la picadura de mosquitos Aedes aegypti infectados con el virus del dengue (DENV, acrónimo oficial), un miembro de la familia Flaviviridae, que afecta principalmente a niños en las regiones tropicales y subtropicales del mundo (1). La mayoría de los pacientes sufren una enfermedad benigna y de resolución espontánea llamada fiebre de dengue, pero un porcentaje de pacientes desarrolla una forma más grave caracterizada por el incremento de la permeabilidad vascular y alteraciones en la hemostasia, denominada fiebre hemorrágica por dengue, que en los estados más graves se manifiesta con choque hipovolémico y se denomina síndrome de choque por dengue o fiebre hemorrágica por dengue grado III o IV, la cual puede ser fatal (2).

Los mecanismos que conducen a la enfermedad grave no están completamente dilucidados. Se cree que la fiebre hemorrágica por dengue se desarrolla en pacientes que sufren una infección secundaria con un serotipo de DENV diferente al de la primera infección, durante la cual las células portadoras del receptor Fc $\gamma$ RII, como monocitos y macrófagos, son infectadas por DENV con opsonina con anticuerpos heterotípicos no neutralizadores generados en la primera infección. Esto conduce a un aumento en el número de células infectadas y a la activación de monocitos y linfocitos $T$ que, finalmente, secretan cantidades desproporcionadas de citocinas y otros mediadores químicos que actúan sobre el endotelio vascular y producen aumento en la permeabilidad vascular, extravasación plasmática y alteraciones en la hemostasia $(3,4)$.

Por otra parte, alrededor de $10 \%$ de los casos de fiebre hemorrágica por dengue ocurren durante infecciones primarias con DENV, usualmente en infantes en la segunda mitad del primer año de vida (5). Se ha postulado que, en estos casos,

Correspondencia:

Jaime E. Castellanos, Grupo de Virología, Universidad El Bosque, Carrera 7B Bis № 132-11, Bogotá, D.C., Colombia.

Teléfono: (571) 648 9066; fax: (571) 6252030

castellanosjaime@unbosque.edu.co

Recibido: 10/11/09; aceptado:03/07/10 la transmisión de anticuerpos maternos no neutralizadores está involucrada en el aumento de células infectadas (6).

Esta red de mediadores y sus múltiples vías reguladoras son muy complejas y se conocen sólo parcialmente en el dengue. Gracias a que los métodos de análisis de expresión global de genes permiten examinar procesos biológicos complejos en un gran contexto, se propuso diferenciar las características de los eventos de transcripción de genes de la respuesta inmunitaria en niños colombianos con fiebre de dengue y fiebre hemorrágica por dengue, por la tecnología de microarreglos. El estudio encontró diferencias en los patrones de expresión génica entre estos dos grupos de pacientes, que pueden brindar nuevas claves sobre los mecanismos que conducen a la enfermedad grave.

\section{Materiales y métodos}

\section{Muestras clínicas}

Se obtuvieron muestras de sangre de seis niños en un rango de edad entre 7 meses y 15 años, que padecían una enfermedad febril de 4 a 7 días de evolución, presuntiva de dengue, en el Hospital Universitario de Neiva y la Institución Prestadora de Salud San Sebastián de La Plata, en el departamento del Huila, Colombia.

El protocolo fue aprobado por el Comité de Ética de la Universidad El Bosque y los acudientes de cada paciente firmaron un consentimiento informado para su inclusión en el estudio.

Las muestras fueron procesadas para obtención de plasma y células mononucleares de sangre periférica por Ficoll Hypaque (Sigma). Las células mononucleares de sangre periférica se trataron con Trizol (Invitrogen) para la extracción del ARN total y, junto con el plasma, se almacenaron a -80 ${ }^{\circ} \mathrm{C}$ hasta su uso.

Los casos de dengue se confirmaron por detección de ARN viral e IgM contra DENV y se clasificaron según su gravedad, siguiendo el criterio de la Organización Mundial de la Salud (7). La serotipificación del DENV se realizó por 
RT-PCR, según el protocolo descrito previamente (8), y el ARN viral fue cuantificado como se reportó previamente (9). La técnica de ultramicro-ELISA (Tecnosuma Intl.) se usó para la detección de anticuerpos IgM e IgG contra DENV en el suero. En los pacientes en cuyas muestras se detectó ARN viral y ausencia de anticuerpos IgG contra DENV, se consideró una infección primaria por DENV, mientras que en aquellos cuyas muestras tenían ARN viral y anticuerpos IgG contra DENV, se consideró una infección secundaria (10). El grupo control consistió de adultos voluntarios sanos, sin ARN viral ni anticuerpos IgM contra DENV detectables $(n=3)$.

\section{Preparación de la muestra e hibridación en el microarreglo}

El procesamiento de las muestras y la hibridación del microarreglo se llevaron a cabo como se publicó anteriormente (11). El ARN total fue nuevamente purificado usando el sistema RNAeasy MiniKit (Quiagen), siguiendo las instrucciones del fabricante. Con $5 \mu \mathrm{g}$ de ARN de cada muestra, se sintetizó el ADNc de cadena sencilla, usando la transcriptasa inversa Superscript II (Invitrogen) y el cebador T7-Oligo(dT) ${ }_{24}$, el cual está diseñado para incorporar la secuencia central del promotor para la ARN polimerasa T7.

Enseguida, se sintetizó el ADN de doble cadena (ADNdsc) con el sistema SuperScript Choice (Invitrogen) y fue purificado con el estuche GeneChip Simple CleanUp Module (Affymetrix). El paso siguiente consistió en generar y marcar con biotina el ARNc; para ello se usó un sistema que, aprovechando la secuencia del promotor de la ARN polimerasa de T7 previamente incorporada, inicia la transcripción in vitro del ADN de doble cadena para sintetizar un ARNc que incorpora nucleótidos biotinilados (GeneChip Expression IVT Labeling, Affymetrix).

Posteriormente, el ARNc se incubó en una solución tampón de fragmentación, que genera por hidrólisis metálica fragmentos de ARNc entre 35 y 200 bases (para una hibridación más eficiente), y esta muestra se inoculó con los genes controles bacterianos bioB, bioC, bio $D$ y cre. Ocho microgramos de cada muestra de este ARNc biotinilado se hibridaron durante 18 horas al microarreglo Affymetrix GeneChip. HG-U133_Plus_2 (38.500 genes) y, al finalizar, se hicieron los lavados correspondientes.

El paso siguiente fue hacer una incubación con estreptavidina acoplada a R-phycoerythrin
(SAPE, Molecular Probes) y luego un proceso de amplificación usando un anticuerpo antiestreptavidina biotinilado (Vector Labs.), para finalizar con una nueva incubación con SAPE. Los microarreglos se leyeron con el equipo GeneArray Scanner (Hewlett-Packard), ubicado en el Center for Infectious Disease and Vaccine Research, University of Massachusetts. Las imágenes obtenidas se analizaron usando la aplicación Affymetrix MAS5, para generar archivos CEL (datos de intensidad media de fluorescencia).

\section{Análisis de datos}

Para el análisis de los datos, los archivos CEL fueron importados al software GeneSpringGX (Agilent). Se hicieron las correcciones de background y normalización mediante un algoritmo matemático sólido (12), usando los datos de intensidad de fluorescencia de cada sonda transformados en su logaritmo de base 2 .

Cada arreglo se normalizó independientemente del valor de intensidad media de fluorescencia de todos los genes en el chip y, posteriormente, cada gen se normalizó al nivel de expresión media de ese gen en todos los arreglos. Los datos con una señal de fluorescencia por debajo del percentil 20 se eliminaron del análisis ( $26 \%$ de los genes).

Los genes expresados diferencialmente en cada grupo de pacientes fueron identificados por un incremento de la intensidad media de fluorescencia para cada gen en, al menos, tres logaritmos respecto a los individuos voluntarios sanos. Las funciones y clasificaciones biológicas de los genes regulados diferencialmente se revisaron por análisis de ontología de genes en el programa EASE (13).

Finalmente, se hizo un análisis de vías biológicas para visualizar redes de regulación de genes y mapas de interacción a partir de grupos de genes expresados diferencialmente, usando la aplicación Pathway Analysis soportada por GeneSpringGX.

\section{Cuantificación de citocinas}

Se cuantificaron los niveles séricos de IL-8 e IL1 $\beta$ utilizando el sistema FlowCytomix Multiplex Quantitation (BMS710FF, Bender MedSystems) en un citómetro DAKO.

\section{Resultados}

\section{Características de los pacientes}

Los hallazgos clínicos y virológicos se presentan en el cuadro 1. Los pacientes incluidos fueron niños entre los 7 meses y los 15 años de edad, en estado 
Cuadro 1. Características clínicas de los pacientes con dengue.

\begin{tabular}{|c|c|c|c|c|c|c|}
\hline \multirow{2}{*}{$\begin{array}{l}\text { Clasificación OMS } \\
\text { Paciente }\end{array}$} & \multicolumn{3}{|c|}{ Fiebre de dengue } & \multicolumn{3}{|c|}{ Fiebre hemorrágica de dengue (IV) } \\
\hline & 1 & 2 & 3 & 4 & 5 & 6 \\
\hline \multicolumn{7}{|l|}{ Síntomas clínicos } \\
\hline Días de evolución & 4 & 4 & 4 & 7 & 5 & 7 \\
\hline Evidencia de extravasación plasmática ${ }^{a}$ & $(-)$ & $(-)$ & $(-)$ & $(+)$ & $(+)$ & $(-)$ \\
\hline Hepatomegalia & $(-)$ & $(-)$ & $(-)$ & $(+)$ & $(+)$ & $(+)$ \\
\hline Choque $^{b}$ & $(-)$ & $(-)$ & $(-)$ & $(+)$ & $(+)$ & $(+)$ \\
\hline \multicolumn{7}{|l|}{ Hallazgos de laboratorio } \\
\hline Plaquetas $\left(10^{3} / \mathrm{mm}^{3}\right)$ & 125 & 129 & ND & 71 & 54 & 58 \\
\hline Anticuerpos IgM & $(+)$ & $(+)$ & $(-)$ & $(+)$ & $(+)$ & $(+)$ \\
\hline Anticuerpos lgG & $(+)$ & $(+)$ & $(-)$ & $(-)$ & $(+)$ & $(+)$ \\
\hline Serotipo dengue & 1 & 1 & 1 & 1 & 1 & 4 \\
\hline Número de copias ARN dengue/ $\mu$ g ARN & 50 & 6,8 & 15 & ND & 1,2 & 17,6 \\
\hline \multicolumn{7}{|l|}{ Otros datos } \\
\hline Historia de la infección ${ }^{c}$ & S & $\mathrm{S}$ & $\mathrm{P}$ & $\mathrm{P}$ & $\mathrm{S}$ & $\mathrm{S}$ \\
\hline Edad en años & 10 & 15 & 12 & 0,7 & 6 & 0,9 \\
\hline Sexo & $\mathrm{F}$ & $\mathrm{M}$ & $\mathrm{M}$ & $\mathrm{M}$ & $\mathrm{F}$ & $\mathrm{M}$ \\
\hline
\end{tabular}

a uno o más de los siguientes síntomas: extravasación plasmática (ascitis o derrame pleural), hemoconcentración mayor de 20\% en el valor de hematocrito

b uno o más de los siguientes síntomas: pulso débil y rápido, hipotensión, presión de pulso estrecha, ausencia de pulso

c infección secundaria $(\mathrm{S})$ o infección primaria $(P)$

ND: no determinado; (+): presente; (-): ausente

febril de 4 a 7 días de evolución. Tres pacientes se clasificaron con fiebre de dengue y, tres, con fiebre hemorrágica de dengue grado IV (síndrome de choque por dengue). Excepto por un paciente infectado con DENV serotipo 4, todos estaban infectados con DENV 1 y no hubo diferencias en la historia de la infección entre los dos grupos.

\section{Genes con aumento de la regulación en las células mononucleares de sangre periférica de ambos grupos de pacientes}

El análisis ontológico de los transcritos, cuya expresión se encontró aumentada en pacientes con fiebre de dengue e, igualmente, aumentada en pacientes con fiebre hemorrágica de dengue, identificó 23 genes asociados con el término "respuesta inmunitaria" ( $p=2,99 \mathrm{E}-13$ ) (cuadro 2). Se encontraron mediadores de la inflamación y actividad de los linfocitos T, como CD69, COX-2, IL-1 $\beta$, IL-8, MIP1-A, PBEF2, CCL3L1, DEFA1 y DEFA2, al igual que reguladores negativos de estas respuestas (TNF-IP3, TSG6, SOD2, RGS1, CTLA4 y CD83). También, se expresaron los factores de transcripción NFKBIA, JUN y NR4A2, esenciales para la activación de los linfocitos y la expresión de muchas citocinas y otros mediadores inmunitarios (14-16), así como el inhibidor de apoptosis BCL2A1, la proteína inducida por interferones IFI27 y las inmunoglobulinas IGHG1, IGHG2 e IGHM.

Teniendo en cuenta que el producto final de muchos de estos transcritos se secreta en el suero, se realizó un ensayo por citometría de flujo para determinar si la expresión de ARNm de IL-1 $\beta$ e IL-8 en células mononucleares de sangre periférica se relaciona con los niveles de estas proteínas en el suero. Efectivamente, el ensayo demostró que los pacientes con fiebre hemorrágica de dengue tenían niveles mayores de $\mathrm{IL}-1 \beta$ que aquellos con fiebre de dengue: $38,7 \mathrm{pg} / \mathrm{ml}(33,4-48,1) \mathrm{Vs}$. $23,9 \mathrm{pg} / \mathrm{ml}(0-39,6)$, respectivamente, al igual que niveles mayores de IL-8: $576,3 \mathrm{pg} / \mathrm{ml}(124,3-$ $1.452,7)$ Vs. $5,5 \mathrm{pg} / \mathrm{ml}(0-16,4)$; esto se relaciona con los resultados encontrados con el análisis de la transcripción (cuadro 2).

\section{Genes diferencialmente expresados entre los grupos de fiebre de dengue y fiebre hemorrágica de dengue}

En el cuadro 3 se presentan los transcritos asociados a la "respuesta inmunitaria" diferencialmente expresados en pacientes con fiebre de dengue. Excepto por PROK2, estos pacientes no expresaron otros mediadores solubles de la inflamación. Algunos promotores de procesos inflamatorios fueron expresados (IL-8RB, CEACAM8 y FOS), así como inhibidores de la expresión de citocinas y complemento (LTF, SERPING1 y CYP4F3). Las inmunoglobulinas (IGHA1, IGHD e IGHV), los receptores FCGR3B y FCGR3A, el inhibidor de apoptosis TRAILR3 y SNCA, también fueron expresados en las células mononucleares de sangre periférica de los pacientes con fiebre de dengue. 
Cuadro 2. Genes de la respuesta inmunitaria con aumento de regulación en las células mononucleares de sangre periférica en casos de fiebre de dengue y de fiebre hemorrágica por dengue.

\begin{tabular}{|c|c|c|c|}
\hline Símbolo & Descripción & $\begin{array}{l}\text { Fiebre de } \\
\text { dengue }^{a}\end{array}$ & $\begin{array}{c}\text { Fiebre hemorrágica } \\
\text { de dengue }{ }^{\mathrm{a}}\end{array}$ \\
\hline BCL2A1 & proteína $\mathrm{A} 1$ relacionada con $\mathrm{BCL} 2$ & 4,3 & 4,5 \\
\hline MIP1-A & proteína 1 alfa inflamatoria de macrófagos (CCL3) & 5,0 & 12,2 \\
\hline CCL3L1 & ligando 1 similar a 3 de quimiocina (motivo $\mathrm{C}-\mathrm{C}$ ) & 5,2 & 7,7 \\
\hline CD69 & molécula CD69 & 4,5 & 8,1 \\
\hline CD83 & molécula CD83 & 4,6 & 7,2 \\
\hline CTLA4 & proteína 4 asociada a linfocitos $T$ citotóxicos & 3,7 & 8,6 \\
\hline DEFA1 & defensina alfa 1 & 6,1 & 6,0 \\
\hline DEFA3 & defensina alfa 3 & 7,9 & 6,3 \\
\hline IFI27 & proteína 27 inducible por interferón & 28,9 & 75,4 \\
\hline IGHG1 & cadena constante de inmunoglobulina gamma 1 & 3,8 & 3,7 \\
\hline IGHG2 & cadena constante de inmunoglobulina gamma 2 & 5,7 & 4,7 \\
\hline IGHM & cadena constante de inmunoglobulina mu & 3,6 & 3,1 \\
\hline IL1B & interleucina 1 beta & 3,1 & 7,3 \\
\hline IL8 & interleucina 8 & 53,7 & 139,4 \\
\hline JUN & oncogen jun & 18,1 & 14,2 \\
\hline NFKBIA & factor nuclear kappa beta & 5,5 & 5,3 \\
\hline NR4A2 & receptor nuclear, subfamilia 4, grupo A, miembro 2 & 6,0 & 12,0 \\
\hline PBEF2 & factor potenciador de colonias de prelinfocitos B & 19,2 & 9,8 \\
\hline $\operatorname{cox}-2$ & ciclooxigenasa 2 & 14,9 & 9,9 \\
\hline RGS1 & regulador de la señalización por proteína G & 6,0 & 21,2 \\
\hline SOD2 & superóxido dismutasa 2 mitocondrial & 3,7 & 9,7 \\
\hline TSG6 & gen 6 inducido por factor de necrosis tumoral & 13,6 & 5,6 \\
\hline TNFAIP3 & proteína 3 inducida por factor de necrosis tumoral & 3,9 & 5,8 \\
\hline
\end{tabular}

${ }^{a}$ Log $_{2}$ del número de veces de incremento en la expresión del gen en los pacientes respecto a los individuos voluntarios sanos. Los resultados corresponden a aquellos genes cuyos transcritos fueron aumentados al menos tres veces en ambos grupos de pacientes (fiebre de dengue y fiebre hemorrágica por dengue) respecto a voluntarios sanos.

Por otra parte, los transcritos exclusivamente expresados en pacientes con fiebre hemorrágica de dengue fueron principalmente mediadores inflamatorios (cuadro 4). En este grupo se encontraron transcritos para las quimiocinas MCP1, MCP3, CXCL1, CXCL2 y CXCL3, complemento C1QA, C1QB, IL-6 y PTX3, así como otros transcritos cuyas proteínas promueven la activación del sistema inmunitario, como PELI1, EDH1, WIP y HAMP. También fueron expresados inhibidores de los linfocitos T, como CTSL1, LAG3 e IL1RN.

\section{Asociaciones funcionales de genes diferencialmente expresados en pacientes con fiebre hemorrágica de dengue}

Para generar un posible modelo de regulación de la respuesta inmunitaria en los pacientes con fiebre hemorrágica de dengue, los genes con aumento de la expresión en este grupo, fueron sometidos a análisis con Pathway Analysis (GeneSpringGX). Este análisis identifica y crea redes de interacción biológicas, usando un algoritmo para extraer el conocimiento desde interacciones moleculares conocidas entre los genes o sus productos. El análisis generó una red de interacciones mediada principalmente por los mediadores proinflamatorios IL-1 $\beta$, IL-1a, FNT-a (factor de necrosis tumoral), IL-6 y CCL2 (MCP-1) y en la cual participa el factor tisular (figura 1).

\section{Discusión}

En este estudio se encontraron similitudes y diferencias en los perfiles de expresión génica entre los pacientes con fiebre de dengue y aquellos con fiebre hemorrágica de dengue, que señalan claves importantes en la patogénesis del dengue. Los pacientes expresaron genes como COX-2, IL-1 $\beta$, IL-8 y MIP1-A, cuyos transcritos son potentes mediadores de la inflamación y han sido previamente reportados en la infección por dengue (17-20), y otros no reportados (PBEF2, CCL3L1, DEFA1 y DEFA2), cuyas proteínas inducen la expresión de citocinas y quimiotaxis (cuadro 2).

En este estudio encontramos una relación entre el aumento de la transcripción del ARNm y la expresión de las proteínas IL-1 $\beta$ e IL-8 en los casos de fiebre de dengue y los de fiebre hemorrágica de dengue. También, se expresaron los genes para potentes inhibidores de la expresión de mediadores inflamatorios y la quimiotaxis (TNFIP3, 
Cuadro 3. Genes de la respuesta inmunitaria con aumento de la expresión en los pacientes con fiebre de dengue a.

\begin{tabular}{llr}
\hline Símbolo & \multicolumn{1}{c}{ Descripción } & Incremento \\
\hline CEACAM8 & molécula de adhesión celular 8 relacionada con el antígeno carcinoembrionario & 3,9 \\
CYP4F3 & leucotrieno B (4)-omega hidroxilasa 2, familia 4 citocromo P450, subfamilia F, polipéptido 3 & 8,2 \\
FCGR3B & fragmento Fc de IgG, baja afinidad IIlb, receptor CD16b & 5,1 \\
FCGR3A & fragmento Fc de IgG, baja afinidad Illa, receptor CD16a & 6,4 \\
FOS & oncogén de osteosarcoma viral v-fos FBJ & 5,3 \\
IGHA1 & cadena constante pesada de inmunoglobulina alfa 1 & 3,3 \\
IGHD & cadena constante pesada de inmunoglobulina delta & 3,5 \\
IGHV & grupo variable de cadena pesada de inmunoglobulina & 3,8 \\
IL8RB & receptor beta de interleucina 8 & 5,5 \\
LTF & Lactotransferrina & 7,4 \\
PROK2 & procineticina 2 & 4,5 \\
SERPING1 & inhibidor peptidasa serpina del complemento C1 & 3,2 \\
SNCA & sinucleína alfa & 3,6 \\
TRAILR3 & receptor 3 de TRAIL (ligando inductor de apoptosis relacionado con FNT) & 6,7 \\
\hline
\end{tabular}

${ }^{a}$ corresponde a aquellos genes con aumento de la expresión tres veces o más en los pacientes con fiebre de dengue y reprimidos, al menos, tres veces en los pacientes con fiebre hemorrágica por dengue.

Cuadro 4. Genes de la respuesta inmunitaria con aumento de la expresión en los pacientes con fiebre hemorrágica por dengue a.

\begin{tabular}{llr}
\hline Símbolo & Descripción & Incremento \\
\hline C1QA & componente 1 del complemento, subcomponente q, cadena A & 3,6 \\
C1QB & componente 1 del complemento, subcomponente q, cadena B & 6,2 \\
MCP-1 & proteína 1 quimiotrayente de monocitos o CCL2 & 33,5 \\
MCP-3 & proteína 3 quimiotrayente de monocitos o CCL7 & 7,7 \\
CXCL1 & ligando 1 de quimiocina (motivo C-X-C) & 4,0 \\
CXCL2 & ligando 2 de quimiocina (motivo C-X-C) & 3,4 \\
CXCL3 & ligando 3 de quimiocina (motivo C-X-C) & 3,1 \\
HAMP & péptido antimicrobiano hepcidina & 3,8 \\
IL1RN & antagonista del receptor de interleucina 1 & 5,4 \\
IL6 & interleucina 6 & 8,8 \\
PTX3 & pentraxina 3 & 17,8 \\
WIP & proteína de interacción con WASp (proteína. del síndrome de Wiskott-Aldrich) & 7,3 \\
CTSL1 & catepsina L1 & 3,0 \\
EHD1 & dominio EH & 3,2 \\
LAG3 & gen 3 de activación de linfocitos & 3,4 \\
PELI1 & pelino 1 & 4,8 \\
SDC1 & sindecan 2 & 3,1 \\
\hline
\end{tabular}

${ }^{a}$ corresponde a aquellos genes que fueron expresados, al menos, cuatro veces más en los pacientes con fiebre hemorrágica por dengue y reprimidos al menos 1,8 veces en los pacientes con fiebre de dengue.

TSG6, SOD2 y RGS1) y CTLA4 y CD83, que son inhibidores de la proliferación y actividad de los linfocitos T (21-25). Estos resultados podrían sugerir que la infección por dengue en los pacientes analizados conduce a una enfermedad inflamatoria que se caracteriza por la expresión concomitante de ARNm, cuyos productos son activadores y supresores del sistema inmunitario.

La información actual indica que las citocinas, el complementoyotrosmediadores producenaumento de la permeabilidad vascular, extravasación de plasma y desequilibrio de la hemostasia, lo cual caracteriza el cuadro de la fiebre hemorrágica de dengue $(3,4)$. Para tratar de encontrar claves que ayuden a entender este modelo de la inmunopatogénesis del dengue, se analizaron las diferencias en los perfiles de expresión génica entre los casos de fiebre de dengue y los de fiebre hemorrágica de dengue (cuadros 3 y 4). Estos análisis demostraron que, excepto por PROK2, los pacientes con fiebre de dengue no expresaron mediadores solubles de la inflamación y, por el contrario, expresaron reguladores de la inflamación, como: la lactotransferrina, que afecta la expresión de citocinas, quimiocinas y otras moléculas efectoras en células presentadoras de antígeno (26), la CYP4F3, una monooxigenasa que inactiva y degrada el leucotrieno B4 (27), y SERPING1, que inhibe el complemento y previene la permeabilidad vascular inducida por lipopolisacáridos (28).

Es muy importante resaltar que dos estudios independientes de análisis de expresión génica 


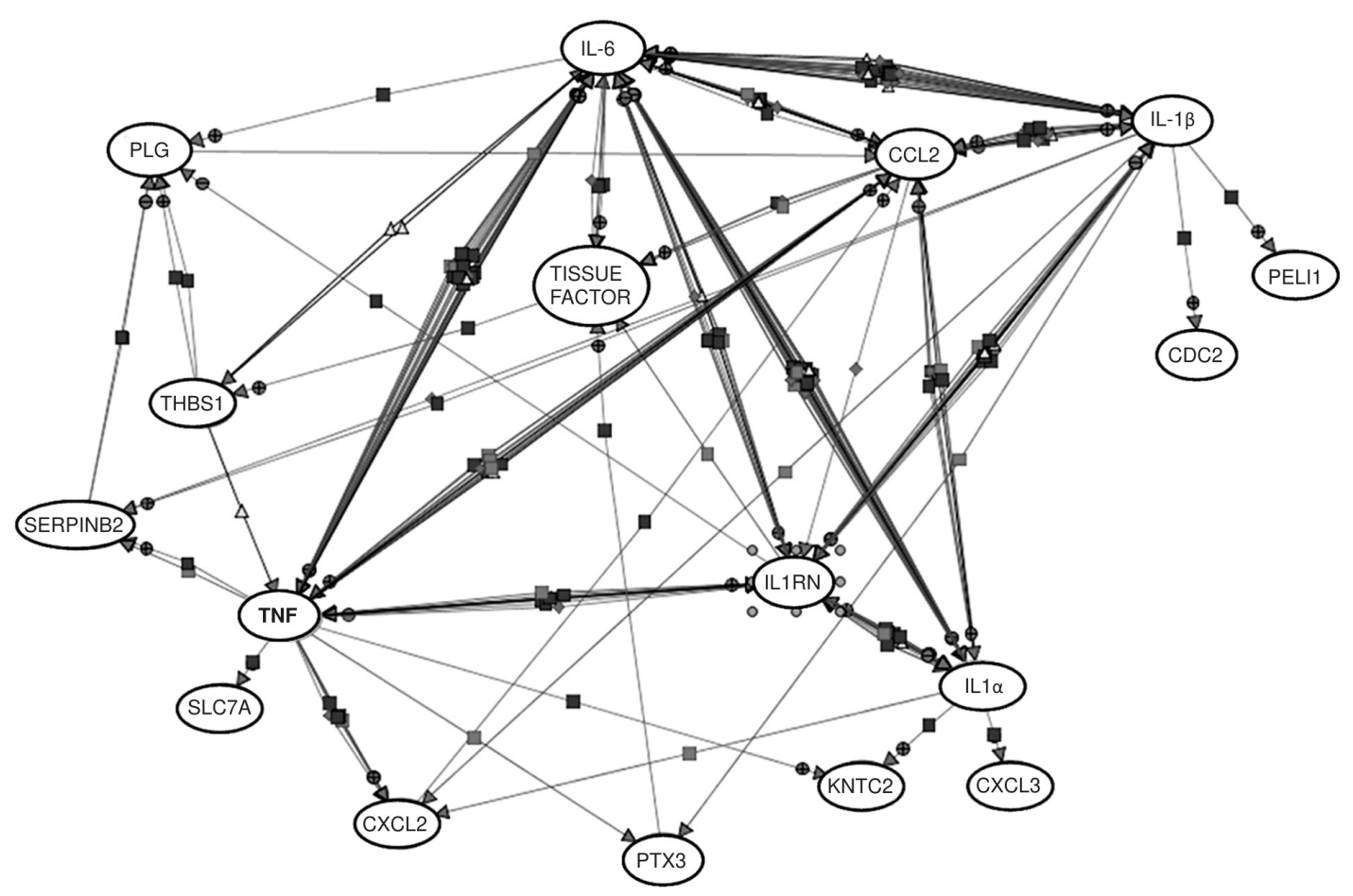

Figura 1. Red de interacción biológica generada por GenespringGX desde los genes expresados en casos de fiebre hemorrágica por dengue pero no en los de fiebre de dengue $(p<0,05)$. Los genes están unidos unos con otros por líneas que representan interacciones de unión o regulación.

también han encontrado que SERPING1 se expresa en pacientes con fiebre de dengue pero no en aquellos con diagnóstico de fiebre hemorrágica de dengue $(29,30)$, lo que indica un papel preponderante para esta molécula, posiblemente como protector de la progresión a cuadros clínicos más graves de la infección. Los hallazgos obtenidos permiten plantear que la acción de las citocinas y del complemento sobre el endotelio vascular logra ser controlada durante la evolución de la infección leve (fiebre de dengue).

A diferencia de los hallazgos vistos en los pacientes con fiebre de dengue, aquellos con fiebre hemorrágica de dengue expresaron gran número de mediadores inflamatorios, como IL-6, MCP1, MCP3, CXCL1, CXCL2, CXCL3, C1QB, C1QA y PTX3 (cuadro 3). Previamente se ha reportado una asociación entre la gravedad y la expresión de IL-6 y MCP-1, así como un papel para estas moléculas en el aumento de la permeabilidad vascular y el desequilibrio hemostático durante los cuadros de fiebre hemorrágica de dengue $(4,31,32)$. La activación del complemento es otra manifestación clínica importante en el dengue grave que contribuye a la extravasación de plasma (33).
También se ha encontrado aumento de los niveles de PTX3 en pacientes con fiebre hemorrágica de dengue-síndrome de choque por dengue (34), aunque su papel en la patogénesis del dengue se desconoce.

Los pacientes con fiebre hemorrágica de dengue expresaron otros transcritosqueindican laactivación del sistema inmunitario, por ejemplo: WIP, que es indispensable para mantener la capacidad citotóxica de las células natural killer (35), EHD1, necesaria para la señalización de la integrina $\beta 1$ (36), PELI 1 , necesaria para la activación de $\mathrm{NF} \kappa \mathrm{B}$ mediada por IL-1 (37), y SCD1, un proteoglucano de sulfato de heparán que media la adhesión y señalización celular en los leucocitos y el endotelio (38). Por otra parte, diferentes estudios han demostrado que en la fiebre hemorrágica de dengue los conteos de linfocitos T están disminuidos, además de que podrían ser incapaces de establecer una respuesta antiviral apropiada, lo que contribuye a la gravedad del cuadro clínico (39-41).

En este estudio, los pacientes con fiebre hemorrágica de dengue expresaron fuertes inhibidores de la actividad de los linfocitos T, como: LAG3, que inhibe su proliferación (42), IL1RN, que 
inhibe la señalización de la IL-1 (43), y CTSL1, un inductor de apoptosis en linfocitos T que entran en anergia por altas dosis de antígeno (44). Varios estudios diferenciales de expresión génica entre la fiebre de dengue y la fiebre hemorrágica de dengue, han demostrado que IL-1RN, CTSL, IL-1B, IL-8 y MCP1 se expresan principalmente en pacientes con fiebre hemorrágica de dengue $(29,30,45)$, lo que resalta la importancia de estas moléculas en su patogénesis.

La expresión de MCP3, CXCL1, CXCL2, CXCL3, WIP, EDH1, PELI1 y SDC1 no ha sido reportada previamente en casos de fiebre hemorrágica de dengue y futuros estudios podrían definir su posible uso como indicadores de gravedad o sus posibles papeles fisiopatológicos en el dengue. Por otra parte, otros estudios también han reportado la expresión de mediadores diferentes a los encontrados en este estudio, como IP-10, MCP-2 y MIP-1 $\beta$ (46).

Hasta el momento, no está completamente clara la forma en que estos mediadores interactúan y conducen a extravasación de plasma y hemorragia en la fiebre hemorrágica de dengue (4); así que, para tratar de generar un posible modelo de interacción, los genes expresados en los pacientes con fiebre hemorrágica de dengue se sometieron a un análisis de vías usando el programa GeneSpringGX. Este análisis generó una red de interacciones moleculares mediadas principalmente por la IL-6, IL-1 $\beta$, IL-1RN, CCL2 (MCP-1) y TNF-a que interactúan con el factor tisular (figura 1).

El factor tisular es el principal regulador de la hemostasia y responsable de iniciar la coagulación sanguínea, cuya expresión aberrante puede conducir a alteraciones de la hemostasia, como la coagulación intravascular diseminada (47). Las citocinas TNF-a, IL-6 e IL-1 $\beta$ parecen ser cruciales en el inicio de la coagulación y fibrinólisis que conducen a alteraciones como la coagulación intravascular diseminada en pacientes con sepsis (48) y, en casos de fiebre hemorrágica de dengue/ síndrome de choque por dengue, se ha demostrado correlación entre estas citocinas y los marcadores de coagulación-fibrinólisis (49), al igual que la relación entre niveles elevados de factor tisular y gravedad (50).

En los casos más graves de fiebre hemorrágica de dengue, la coagulación intravascular diseminada es un mecanismo que conduce a sangrado (51), por lo que el factor tisular podría jugar un papel en la patogénesis del sangrado en estos pacientes y representar un blanco terapéutico interesante. La razón por la cual el ARNm para el factor tisular no se detectó en las células mononucleares de sangre periférica de los pacientes con fiebre hemorrágica de dengue, podría ser consecuencia de su dinámica de expresión. El factor tisular es un gen de respuesta inmediata (52), cuya expresión inicial podría no ser regulada a nivel de la transcripción, sino por traslocación de la proteína en compartimientos celulares y secretores. Sin embargo, la interacción generada por el análisis de vías entre otros genes asociados a la actividad de factor tisular que sí tienen control de la transcripción, indican una función del factor tisular en la fiebre hemorrágica de dengue.

A pesar de que los cambios en los niveles de ARNm detectados por microarreglos no reflejan procesos posteriores críticos para la expresión de un producto génico funcional, y además el muestreo de los niveles de ARN en un punto dado del tiempo es una medida estadística que puede no reflejar completamente la dinámica de expresión génica, estas observaciones derivadas de la evaluación simultánea de diferentes transcritos en un tipo de muestra fácilmente obtenible, como son las células mononucleares de sangre periférica, y que refleja las condiciones de la periferia, son herramientas poderosas y confiables que añaden nueva información, guían diseños experimentales que pueden conducir a un mejor entendimiento de aquellos procesos asociados con la respuesta inmunitaria en la infección por DENV y brindan claves importantes que ayudan a entender la manera como la respuesta inmunitaria participa en la patogénesis de la fiebre hemorrágica de dengue.

Es posible que exista un efecto de la edad sobre la expresión de los genes encontrados en este estudio, que podría estar relacionado, por ejemplo, con los procesos propios del desarrollo del sistema inmunitario durante la infancia. Hasta donde conocemos, no existen reportes de la forma en que la edad podría afectar este grupo particular de genes. Igualmente, hay que considerar que las variabilidades dependerán de las respuestas específicas de cada paciente; de allí la importancia de realizar estudios con cohortes más grandes y analizar las respuestas que se obtengan como común denominador en todos los estudios publicados.

En conclusión, los pacientes con fiebre hemorrágica de dengue expresaron transcritos para mediadores 
inflamatorios (IL-6, MCP1, MCP3, CXCL1, CXCL2, CXCL3, C1QA, C1QB, PTX3) e inhibidores de los linfocitos (LAG3, CTSL1), y la interacción teórica de estos genes desarrolla una red donde el factor tisular es central. Por el contrario, los pacientes con fiebre de dengue, expresaron inhibidores de la inflamación (LTF, SERPING, CYP4F3). Estos resultados, en conjunto, sugieren que casos de fiebre hemorrágica de dengue la interacción de citocinas, quimiocinas y otros mediadores solubles, sumada a una respuesta alterada por parte de los linfocitos $T$, produce aumento en la permeabilidad vascular, extravasación de plasma, alteraciones de la hemostasia y, finalmente, choque. Mientras que, en los pacientes con fiebre de dengue, la acción de inhibidores del complemento y las quimiocinas controla el daño al endotelio vascular y el desarrollo de enfermedad grave. Los futuros estudios que validen la participación y papel en la patogénesis del dengue de las moléculas identificadas en este estudio, contribuirán a la interpretación de la patogenia y al desarrollo racional de fármacos.

\section{Agradecimientos}

Los autores agradecen a Doris Salgado del Hospital Universitario de Neiva y Limbania Perdomo Houghton de la Institución Prestadora de Salud San Sebastián de La Plata, Huila, por la donación de las muestras de los pacientes incluidos en este estudio. Los autores también desean agradecer a Jeannette Prada-Arismendy por la realización de los ensayos de serotipificación del virus dengue.

\section{Conflicto de intereses}

Los autores no tienen ningún conflicto de interés en los productos o conceptos mencionados en este manuscrito.

\section{Financiación}

Este trabajo fue financiado por Colciencias (proyecto 130-8343-19249), la Universidad El Bosque y por el Center for Infectious Disease and Vaccine Research, de la Universidad de Massachussets.

\section{Referencias}

1. Mackenzie JS, Gubler DJ, Petersen LR. Emerging flaviviruses: The spread and resurgence of Japanese encephalitis, West Nile and dengue viruses. Nat Med. 2004;10:S98-109.

2. Organización Mundial de la Salud. Dengue hemorrhagic fever and dengue shock syndrome in the context of the integrated management of childhood illness. Ginebra: World Health Organization; 2005. Fecha de consulta: 7 de febrero de 2009. Disponible en: http://www.who.int/
childadolescenthealth/New_Publications/CHILD_HEALTH/ DP/WHO_FCH_CAH_013.pdf.

3. Martínez-Gutiérrez $\mathbf{M}$, Castellanos JE. Dengue hemorrágico. ¿Una aberración inmunológica? Revista Escuela Colombiana de Medicina. 2006;11:10-9.

4. Kurane I. Dengue hemorrhagic fever with special emphasis on immunopathogenesis. Comp Immunol Microbiol Infect Dis. 2007;30:329-40.

5. Green S, Rothman A. Immunopathological mechanisms in dengue and dengue hemorrhagic fever. Curr Opin Infect Dis. 2006;19:429-36.

6. Kliks SC, Nimmanitya S, Nisalak A, Burke DS. Evidence that maternal dengue antibodies are important in the development of dengue hemorrhagic fever in infants. Am J Trop Med Hyg. 1988;38:411-9.

7. Organización Mundial de la Salud. Dengue hemorrhagic fever: Diagnosis, treatment, prevention and control. Chapter 2. Clinical diagnosis. Geneve: World Health Organization; 1997. Fecha de consulta: 12 de noviembre de 2008. Disponible en: http://www.who.int/csr/resources/ publications/dengue/012-23.pdf.

8. Chien LJ, Liao TL, Shu PY, Huang JH, Gubler DJ, Chang GJ. Development of real-time reverse transcriptase PCR assays to detect and serotype dengue viruses $\mathrm{J}$ Clin Microbiol. 2006;44:1295-304.

9. Prada-Arismendy J, Castellanos JE. Real time PCR. Application in dengue studies. Colomb Med. 2010, in press.

10. Chen RF, Liu JW, Yeh WT, Wang L, Chang JC, Yu HR, et al. Altered T helper 1 reaction but not increase of virus load in patients with dengue hemorrhagic fever. FEMS Immunol Med Microbiol. 2005;44:43-50.

11. Warke RV, Xhaja K, Martin KJ, Fournier MF, Shaw SK, Brizuela $\mathbf{N}$, et al. Dengue virus induces novel changes in gene expression of human umbilical vein endothelial cells. J Virol. 2003;77:11822-32.

12. Irizarry RA, Hobbs B, Collin F, Beazer-Barclay YD, Antonellis $\mathrm{KJ}$, Scherf $\mathrm{U}$, et al. Exploration, normalization, and summaries of high density oligonucleotide array probe level data. Biostatistics. 2003;4:249-64.

13. Hosack DA, Dennis G Jr, Sherman BT, Lane HC, Lempicki RA. Identifying biological themes within lists of genes with EASE. Genome Biol. 2003;4:R70.

14. Hayden MS, West AP, Ghosh S. NF-kappaB and the immune response. Oncogene. 2006;25:6758-80.

15. Wang M, Windgassen D, Papoutsakis ET. Comparative analysis of transcriptional profiling of CD3+, CD4+ and CD8+ $T$ cells identifies novel immune response players in T-cell activation. BMC Genomics. 2008;9:225.

16. Zenz R, Eferl R, Scheinecker C, Redlich K, Smolen J, Schonthaler HB, et al. Activator protein 1 (Fos/Jun) functions in inflammatory bone and skin disease. Arthritis Res Ther. 2008;10:201-6.

17. Bozza FA, Cruz OG, Zagne SM, Azeredo EL, Nogueira RM, Assis EF, et al. Multiplex cytokine profile from dengue patients: MIP-1beta and IFN-gamma as predictive factors for severity. BMC Infect Dis. 2008;8:86-97. 
18. Liou JT, Chen ZY, Ho LJ, Yang SP, Chang DM, Liang CC, et al. Differential effects of triptolide and tetrandrine on activation of COX-2, NF-kappaB, and AP-1 and virus production in dengue virus-infected human lung cells. Eur $\mathrm{J}$ Pharmacol. 2008;589:288-98.

19. Raghupathy R, Chaturvedi UC, Al-Sayer H, Elbishbishi EA, Agarwal R, Nagar R, et al. Elevated levels of IL-8 in dengue hemorrhagic fever. J Med Virol. 1998;56:280-5.

20. Suharti C, van Gorp EC, Setiati TE, Dolmans WM, Djokomoeljanto RJ, Hack CE, et al. The role of cytokines in activation of coagulation and fibrinolysis in dengue shock syndrome. Thromb Haemost. 2002;87:42-6.

21. Coornaert B, Carpentier I, Beyaert R. A20: Central gatekeeper in inflammation and immunity. J Biol Chem. 2009;284:8217-21.

22. Milner CM, Higman VA, Day AJ. TSG-6: a pluripotent inflammatory mediator? Biochem Soc Trans. 2006;34:44650.

23. Yasui K, Baba A. Therapeutic potential of superoxide dismutase (SOD) for resolution of inflammation. Inflamm Res. 2006;55:359-63.

24. Gough SC, Walker LS, Sansom DM. CTLA4 gene polymorphism and autoimmunity. Immunol Rev. 2005;204:102-15.

25. Fujimoto $\mathbf{Y}$, Tedder TF. CD83: A regulatory molecule of the immune system with great potential for therapeutic application. J Med Dent Sci. 2006;53:85-91.

26. Puddu P, Valenti P, Gessani S. Immunomodulatory effects of lactoferrin on antigen presenting cells. Biochimie. 2009;91:11-8.

27. Christmas P, Tolentino K, Primo V, Berry KZ, Murphy RC, Chen M, et al. Cytochrome P-450 4F18 is the leukotriene B4 omega-1/omega-2 hydroxylase in mouse polymorphonuclear leukocytes: identification as the functional orthologue of human polymorphonuclear leukocyte CYP4F3A in the down-regulation of responses to LTB4. J Biol Chem. 2006;281:7189-96.

28. Cheng ZD, Liu MY, Chen G, Zhang HM, Qin GJ, Liang G, et al. Anti-vascular permeability of the cleaved reactive center loop within the carboxyl-terminal domain of $\mathrm{C} 1$ inhibitor. Mol Immunol. 2008;45:1743-51.

29. Ubol S, Masrinoul P, Chaijaruwanich J, Kalayanarooj $\mathrm{S}$, Charoensirisuthikul T, Kasisith J. Differences in global gene expression in peripheral blood mononuclear cells indicate a significant role of the innate responses in progression of dengue fever but not dengue hemorrhagic fever. J Infect Dis. 2008;197:1459-67.

30. Long HT, Hibberd ML, Hien TT, Dung NM, Van Ngoc T, Farrar $\mathrm{J}$, et al. Patterns of gene transcript abundance in the blood of children with severe or uncomplicated dengue highlight differences in disease evolution and host response to dengue virus infection. J Infect Dis. 2009;199:537-46.

31. Suharti C, van Gorp EC, Dolmans WM, Setiati TE, Hack CE, Djokomoeljanto $\mathbf{R}$, et al. Cytokine patterns during dengue shock syndrome. Eur Cytokine Netw. 2003;14:172-7.

32. Lee YR, Liu MT, Lei HY, Liu CC, Wu JM, Lin YS, et al. MCP-1, a highly expressed chemokine in dengue haemorrhagic fever/dengue shock syndrome patients, may cause permeability change, possibly through reduced tight junctions of vascular endothelium cells. J Gen Virol. 2006;87:3623-30.

33. Avirutnan P, Punyadee N, Noisakran S, Komoltri C, Thiemmeca S, Auethavornanan $\mathrm{K}$, et al. Vascular leakage in severe dengue virus infections: A potential role for the nonstructural viral protein NS1 and complement. J Infect Dis. 2006;193:1078-88.

34. Mairuhu AT, Peri G, Setiati TE, Hack CE, Koraka P, Soemantri A, et al. Elevated plasma levels of the long pentraxin, pentraxin 3 , in severe dengue virus infections. J Med Virol. 2005;76:547-52.

35. Krzewski K, Chen X, Strominger JL. WIP is essential for lytic granule polarization and NK cell cytotoxicity. Proc Natl Acad Sci USA. 2008;105:2568-73.

36. Jovic M, Naslavsky N, Rapaport D, Horowitz M, Caplan S. EHD1 regulates beta1 integrin endosomal transport: effects on focal adhesions, cell spreading and migration. $J$ Cell Sci. 2007;120:802-14.

37. Jiang Z, Johnson HJ, Nie H, Qin J, Bird TA, Li X. Pellino 1 is required for interleukin-1 (IL-1)-mediated signaling through its interaction with the IL-1 receptor-associated kinase 4 (IRAK4)-IRAK-tumor necrosis factor receptorassociated factor 6 (TRAF6) complex. J Biol Chem. 2003;278:10952-6.

38. Lopes CC, Dietrich CP, Nader HB. Specific structural features of syndecans and heparan sulfate chains are needed for cell signaling. Braz J Med Biol Res. 2006;39:15767.

39. Green S, Pichyangkul S, Vaughn DW, Kalayanarooj S, Nimmannitya S, Nisalak A, et al. Early CD69 expression on peripheral blood lymphocytes from children with dengue hemorrhagic fever. J Infect Dis. 1999;180:1429-35.

40. Mathew A, Kurane I, Green S, Vaughn DW, Kalayanarooj S, Suntayakorn S, et al. Impaired T cell proliferation in acute dengue infection. J Immunol. 1999;162:5609-15.

41. Simmons CP, Dong T, Chau NV, Dung NT, Chau TN, Thao le TT, et al. Early T-cell responses to dengue virus epitopes in Vietnamese adults with secondary dengue virus infections. J Virol. 2005;79:5665-75.

42. Workman CJ, Cauley LS, Kim IJ, Blackman MA, Woodland DL, Vignali DA. Lymphocyte activation gene-3 (CD223) regulates the size of the expanding $T$ cell population following antigen activation in vivo. J Immunol. 2004;172:5450-5.

43. Dinarello CA. Blocking IL-1 in systemic inflammation. J Exp Med. 2005;201:1355-9.

44. Michallet MC, Saltel F, Flacher M, Revillard JP, Genestier L. Cathepsin-dependent apoptosis triggered by supraoptimal activation of T lymphocytes: a possible mechanism of high dose tolerance. J Immunol. 2004;172:5405-14.

45. Simmons CP, Popper S, Dolocek C, Chau TN, Griffiths M, Dung NT, et al. Patterns of host genome-wide gene transcript abundance in the peripheral blood of patients with acute dengue hemorrhagic fever. $J$ Infect Dis. 2007; 195:1097-107.

46. Becerra A, Warke RV, Martin K, Xhaja K, de Bosch N, Rothman AL, et al. Gene expression profiling of dengue 
infected human primary cells identifies secreted mediators in vivo. J Med Virol. 2009;81:1403-11.

47. Maly MA, Tomasov $P$, Hájek $P$, Blasko P, Hrachovinová I, Salaj $\mathbf{P}$, et al. The role of tissue factor in thrombosis and hemostasis. Physiol Res. 2007;56:685-95.

48. Schouten M, Wiersinga WJ, Levi M, van der Poll T. Inflammation, endothelium, and coagulation in sepsis. $J$ Leukoc Biol. 2008;83:536-45.

49. Suharti C, van Gorp EC, Setiati TE, Dolmans WM, Djokomoeljanto RJ, Hack CE, et al. The role of cytokines in activation of coagulation and fibrinolysis in dengue shock syndrome. Thromb Haemost. 2002;87:42-6.
50. Sosothikul D, Seksarn P, Pongsewalak S, Thisyakorn U, Lusher J. Activation of endothelial cells, coagulation and fibrinolysis in children with dengue virus infection. Thromb Haemost. 2007;97:627-34.

51. Srichaikul T, Nimmannitya S. Haematology in dengue and dengue haemorrhagic fever. Baillieres Best Pract Res Clin Haematol. 2000;13:261-76.

52. Hetland O, Brovold AB, Holme R, Gaudernack G, Prydz H. Thromboplastin (tissue factor) in plasma membranes of human monocytes. Biochem J. 1985;228:735-43. 